\title{
Feasibility and outcome of the Rotapro system in treating severely calcified coronary lesions: The Rotapro study
}

\author{
Mohamed Ayoub ${ }^{1}$, Peter Tajti ${ }^{1,2}$, Miroslaw Ferenc ${ }^{1}$, Ibrahim Akin ${ }^{3}$, \\ Michael Behnes ${ }^{3}$, Franz-Josef Neumann ${ }^{1}$, Kambis Mashayekhi ${ }^{1}{ }^{\circledR}$ \\ ${ }^{1}$ Division of Cardiology and Angiology II, University Heart Center Freiburg, Bad Krozingen, Germany \\ ${ }^{2}$ Gottsegen György Hungarian Institute of Cardiology, Budapest, Hungary \\ ${ }^{3}$ First Department of Medicine, University Medical Center Mannheim (UMM), \\ Faculty of Medicine Mannheim, University of Heidelberg, Mannheim, Germany
}

\begin{abstract}
Background: The Rotapro study was conducted to evaluate the safety and feasibility of the new Rotapro rotational atherectomy system (RAS) for lesion preparation in calcified coronary artery stenosis.

Methods: Between 2015 and 2019 consecutive patients undergoing rotational atherectomy (RA) with the new Rotapro system and the conventional rotablator (Rotablator) were included from the Bad Krozingen Rotablation Registry. The primary endpoint was the incidence of in-hospital major adverse cardiovascular and cerebral event (MACCE) rate.

Results: Rotablation was performed in $3.6 \%$ of all patients $(n=597)$ treated by percutaneous coronary intervention. Procedural outcomes were compared according to the applied RAS ( $n=246$ Rotapro vs. $n=351$ Rotablator). Overall technical success was achieved in $98.3 \%$ of patients. The primary endpoint of in-hospital MACCE was comparable between the Rotapro- and the Rotablator-group (3.7\% vs. 5.7\%, respectively, $p=0.254$ ). The Rotapro group was associated with significant reductions of fluoroscopy time (30 vs. $38 \mathrm{~min}, p<0.0001$ ), procedural time (82.5 vs. $96 \mathrm{~min}, p=0.0003$ ), applied contrast volume (210 vs. $290 \mathrm{~mL}, p<0.0001)$ and radiation dose (6129vs. $\left.9827 \mathrm{cGy} * \mathrm{~cm}^{2}, p<0.0001\right)$ compared to the Rotablator group.

Conclusions: The present study demonstrates the safety and efficacy of the new Rotapro system. Inhospital MACCE rates were comparable between both RAS, whereas Rotapro was associated with less fluoroscopy time, radiation dose as well as contrast use. (Cardiol J)
\end{abstract}

Key words: percutaneous coronary intervention, rotational atherectomy, coronary artery disease

\section{Introduction}

Treatment of calcified lesions with percutaneous coronary intervention (PCI) has ben improved during recent years [1]. PCI of calcified coronary lesions remains challenging regarding optimal stent delivery and expansion [2]. Adequate lesion preparation is fundamental for sufficient stent expansion prior to stent implantation. Nevertheless, $\mathrm{PCI}$ of calcified lesions is associated with higher rates of re-stenosis and target lesion failure [3]. Rotational atherectomy (RA) is considered as an

Address for correspondence: Dr. Kambis Mashayekhi, MD, Department of Cardiology and Angiology II, University Heart Center Freiburg; Bad Krozingen, Suedring 15, 79189 Bad Krozingen, Germany, tel: +49 (0) 76334022105 , fax: +49 (0) 7633 4022409, e-mail: Kambis.Mashayekhi@universitaets-herzzentrum.de

Received: 28.06.2021 Accepted: 30.07.2021 Early publication date: 18.10.2021

This article is available in open access under Creative Common Attribution-Non-Commercial-No Derivatives 4.0 International (CC BY-NC-ND 4.0) license, allowing to download articles and share them with others as long as they credit the authors and the publisher, but without permission to change them in any way or use them commercially. 
important device for stent delivery and complete stent expansion in calcified lesions [4, 5]. Recently, Abdel-Wahab et al. [6] showed the feasibility of using RA in patients with severely calcified lesions without excessive late lumen loss in the randomized PREPARE-CALC trial. The present study analyzed patients with calcified lesions undergoing PCI using RA with either the new Rotapro rotational atherectomy system (RAS) or the conventional Rotablator (Boston Scientific, Natick, MA, USA) followed by drug-eluting-stent implantation.

\section{Methods}

\section{Study population}

Patients undergoing PCI with RA were included in the Bad Krozingen rotablation registry from January 2015 to December 2019. In September 2018, the new RAS from Boston scientific (Rotapro) was installed at the documented institution. Data collection included all patients treated by RA in severely calcified lesions with either the new Rotapro RAS or the conventional Rotablator. Written informed consent for PCI was obtained from each patient and the collection of data was performed in accordance with the Declaration of Helsinki and was approved by the institutional review board (Ethical approval number: EK 21-1100). All angiographic results were analyzed by two independent interventional cardiologists reviewing coronary angiograms and procedure-related data were obtained retrospectively from source data and related documentation.

\section{Rotational atherectomy procedure and postinterventional management}

The decision to perform RA was at the operators' discretion and RA was performed upfront due to heavy calcification of the target lesion or after failed PCI attempts due to non-dilatable or uncrossable calcified lesion. Severe calcification of the target lesion was defined by cine angiography (i.e. radiopacities noted without cardiac motion before contrast injection generally compromising both sides of the arterial lumen) [7]. All RA PCI were performed by high-volume PCI operators using Rotablator and since September 2018 the Rotapro RAS (Boston Scientific Corp., Natick, MA) (i.e. defined by a minimum of $n=50$ RAs performed each year). Vascular access, burr size and ablation speed were left to the operators' discretion. Heparin and nitroglycerin were given during RA as continuous infusion. Atropin was given prior to RA and pacemaker was present just in case of persistent bradycardia after atropin as recommended [8]. The initial burr size was chosen by the operators due to the reference vessel diameter (burr: artery ratio $\leq 0.7$ ) [9]. RA speed was chosen by the operators and RA was started over a Rotawire ${ }^{\mathrm{TM}}$ (Boston Scientific) with an initial rotational speed of $160.000 \mathrm{rpm}$ to $180.000 \mathrm{rpm}$. Postinterventional 12 leads electrocardiogram were documented 24 hours after PCI and cardiac markers (CK, CK-MB and troponin) were measured after 8, 16 and 24 hours. In addition, patients were clinically monitored during the whole hospital stay.

\section{Study endpoints}

The primary endpoint was the incidence of inhospital major adverse cardiovascular and cerebral event (MACCE) rate defined as the composite of in-hospital all-cause death, periprocedural myocardial infarction, recurrent symptoms requiring urgent target vessel revascularization with PCI or surgery, and stroke. Periprocedural myocardial infarction was defined using by the fourth universal definition (type 4a) [10].

Secondary endpoints were procedural success, defined as technical success without in-hospital MACCE, procedural time, fluoroscopy time, the amount of contrast used, as well as major complications defined as vascular access complications and pericardiocentesis. Technical success was defined as successful revascularization of occlusive and non-occlusive coronary lesions with achievement of $<30 \%$ residual diameter stenosis within the treated segment and restoration or maintenance of Thrombolysis in Myocardial Infarction (TIMI) grade 3 antegrade flow.

\section{Statistical analysis}

The continuous data are presented as mean \pm standard deviation or median (interquartile range $[\mathrm{IQR}]$ ) unless otherwise specified and were compared using the Student t-test. Wilcoxon ranksum test and the Kruskal-Wallis test were applied for non-parametric continuous variables, as appropriate. Categorical variables were expressed as percentages and were compared using the Pearson $\chi^{2}$ test or Fisher exact test. Multivariable logistic regression model with backward elimination were developed using the primary endpoint of in-hospital MACCE as the dependent variable. Furthermore, multivariable logistic regression models with backward elimination were developed using fluoroscopy time above the median of each evaluated subgroup as the dependent variable. The 
Table 1. Baseline characteristics in patients undergoing rotational atherectomy.

\begin{tabular}{|c|c|c|c|c|}
\hline Patient characteristics & $\begin{array}{c}\text { Overall } \\
\text { (n = 597) }\end{array}$ & $\begin{array}{l}\text { Rotapro } \\
(\mathrm{n}=246)\end{array}$ & $\begin{array}{l}\text { Rotablator } \\
(\mathrm{n}=351)\end{array}$ & $\mathbf{P}$ \\
\hline Age [years] ${ }^{a}$ & $72.9 \pm 9.1$ & $73.0 \pm 9.0$ & $72.8 \pm 9.2$ & 0.71 \\
\hline Men & $79.7 \%$ & $78.9 \%$ & $80.3 \%$ & 0.65 \\
\hline BMI $\left[\mathrm{kg} / \mathrm{m}^{2}\right]$ & $27.7 \pm 4.4$ & $27.7 \pm 4.1$ & $27.8 \pm 4.5$ & 0.78 \\
\hline eGFR $\left[\mathrm{mL} / \mathrm{min} / 1.73 \mathrm{~m}^{2}\right]$ & $66.3 \pm 21.0$ & $65.7 \pm 20.25$ & $64.65 \pm 22.5$ & 0.55 \\
\hline Heart failure & (37) $6.3 \%$ & (12) $5.1 \%$ & (25) $7.1 \%$ & 0.34 \\
\hline NYHA classification: & & & & 0.34 \\
\hline I & (89) $14.9 \%$ & (45) $18.3 \%$ & (44) $12.6 \%$ & \\
\hline II & (272) $45.5 \%$ & (111) $45.2 \%$ & (160) $45,7 \%$ & \\
\hline III & (212) $35.5 \%$ & (80) $32.5 \%$ & (132) $37.5 \%$ & \\
\hline IV & (24) $4.1 \%$ & (10) $4.1 \%$ & (14) $4.1 \%$ & \\
\hline CAD presentation: & & & & $0.02^{*}$ \\
\hline ACS & (100) $16.8 \%$ & (31) $12.6 \%$ & (69) $19.7 \%$ & \\
\hline No ACS & (497) $83.2 \%$ & (215) $87.4 \%$ & (282) $80.3 \%$ & \\
\hline СТО vessel & (216) $36.2 \%$ & (90) $36.7 \%$ & (126) $35.9 \%$ & 0.83 \\
\hline Diabetes mellitus & (224) $37.6 \%$ & (86) $35.1 \%$ & (138) $39.3 \%$ & 0.32 \\
\hline Dyslipidemia & (537) $90.0 \%$ & (233) $94.3 \%$ & (304) $87,1 \%$ & $0.006^{*}$ \\
\hline Hypertension & (552) $92.5 \%$ & (222) $90.3 \%$ & (330) 93,8\% & 0.11 \\
\hline Current smoker & (63) $10.5 \%$ & (24) $9.8 \%$ & (39) $11,0 \%$ & 0.65 \\
\hline LVEF [\%]: & & & & 0.37 \\
\hline$>51$ & (381) $63.9 \%$ & (163) $66.4 \%$ & (218) $62.2 \%$ & \\
\hline $41-51$ & (116) $19.4 \%$ & (40) $16.2 \%$ & (76) $21.8 \%$ & \\
\hline $30-40$ & (63) $10.6 \%$ & (29) $11.8 \%$ & (34) $9.8 \%$ & \\
\hline $0-29$ & (36) $6.1 \%$ & (14) $5.7 \%$ & (16) $6.3 \%$ & \\
\hline Family history of CAD & (206) $34.6 \%$ & (84) $34.0 \%$ & (122) $35.0 \%$ & 0.82 \\
\hline Prior MI & (206) $34.5 \%$ & (78) $31.9 \%$ & (128) $36.3 \%$ & 0.30 \\
\hline Prior CABG & (180) $30.1 \%$ & (59) $23.9 \%$ & (121) $34.4 \%$ & $0.009^{*}$ \\
\hline Prior stroke & (8) $1.3 \%$ & (17) $0.4 \%$ & (7) $2.0 \%$ & 0.10 \\
\hline LDL max. [mg/dL] & $95.8 \pm 35.8$ & $95.2 \pm 37.4$ & $96.2 \pm 34.7$ & 0.74 \\
\hline Positive stress test & (478) $80.0 \%$ & (218) $88.4 \%$ & (260) $73.6 \%$ & 0.02 \\
\hline
\end{tabular}

Values are given as percentages of patients and numbers or as mean and standard deviation. * Statistically significant with $\mathrm{p}<0.05$; ACS acute coronary syndrome; BMI — body mass index; CABG — coronary artery bypass grafting; CAD — coronary artery disease; CTO — chronic total occlusion; eGFR - estimated glomerular filtration rate; LDL — low-density lipoprotein; LVEF — left ventricular ejection fraction; $\mathrm{MI}$ - myocardial infarction; NYHA - New York heart Association; PCI - percutaneous coronary intervention

multivariable models were adjusted for confounding independent variables, which were significantly different between the Rotapro and the Rotablator group regarding baseline, angiographic and PCI-related characteristics. Corresponding odds ratios with $95 \%$ confidence intervals (95\% CI) were presented. All statistical analyses were performed with JMP 13.0 (SAS, Cary, North Carolina, USA). A two-sided $p$ value of 0.05 was considered statistically significant.

\section{Results}

\section{Baseline and angiographic characteristics}

Out of 16,317 PCIs from 2015 to 2019, a total of 597 (3.6\%) consecutive PCI with RA were included. The Rotapro RAS was used in $246(41.2 \%)$, whereas the Rotablator was used in 351 (58.8\%) PCI. Baseline and angiographic characteristics are outlined in Tables 1-3. Acute coronary syndromes, prior coronary artery bypass grafting, excentric calcified lesion 
Table 2. Characteristics retrieved from coronary angiography

\begin{tabular}{|c|c|c|c|c|}
\hline Lesion characteristics & $\begin{array}{l}\text { Overall } \\
(n=597)\end{array}$ & $\begin{array}{l}\text { Rotapro } \\
(n=246)\end{array}$ & $\begin{array}{l}\text { Rotablator } \\
\text { (n = 351) }\end{array}$ & $\mathbf{P}$ \\
\hline Target vessel: & & & & 0.095 \\
\hline Left main & (86) $14.4 \%$ & (35) $14.2 \%$ & (51) $14.5 \%$ & \\
\hline Right coronary artery & (250) $41.9 \%$ & (95) $38.6 \%$ & (155) $44.2 \%$ & \\
\hline Left circumflex artery & $(100) 16.7 \%$ & (37) $15.0 \%$ & (63) $17.9 \%$ & \\
\hline Left anterior descending artery & (159) $26.6 \%$ & (79) $32.1 \%$ & (80) $22.8 \%$ & \\
\hline Single vein graft & (2) $0.3 \%$ & (0) $0.0 \%$ & (2) $0.6 \%$ & \\
\hline Lesion length [mm]: & & & & 0.151 \\
\hline$<10 \mathrm{~mm}$ & (21) $3.6 \%$ & (9) $3.8 \%$ & (12) $3.5 \%$ & 0.922 \\
\hline $10-20 \mathrm{~mm}$ & (161) $27.1 \%$ & (68) $28.3 \%$ & (93) $27.0 \%$ & \\
\hline$>20 \mathrm{~mm}$ & (405) $68.0 \%$ & (163) $67.9 \%$ & (240) $69.5 \%$ & \\
\hline AHA/ACC classification: & & & & 0.531 \\
\hline $\mathrm{A} / \mathrm{B} 1$ & (12) $2.1 \%$ & (6) $2.5 \%$ & (6) $1.7 \%$ & \\
\hline B2 & (108) $18.1 \%$ & (48) $19.6 \%$ & (60) $17.1 \%$ & \\
\hline $\mathrm{C}$ & (476) $79.8 \%$ & $(191) 78.0 \%$ & $(285) 81.2 \%$ & \\
\hline Calcification: & & & & 0.886 \\
\hline None & (4) $0.7 \%$ & (2) $0.4 \%$ & (2) $0.6 \%$ & \\
\hline Mild & (14) $2.3 \%$ & (7) $2.9 \%$ & (7) $2.0 \%$ & \\
\hline Moderate & (70) $11.7 \%$ & (30) $12.2 \%$ & (40) $11.4 \%$ & \\
\hline Severe & $(508) 85.2 \%$ & (207) $84.5 \%$ & (301) $86.0 \%$ & \\
\hline Excentric calcification & (357) $59.7 \%$ & (123) $50.4 \%$ & (234) $66.7 \%$ & $0.0001^{*}$ \\
\hline Tortuosity & (143) $24.1 \%$ & (52) $21.3 \%$ & (91) $26.1 \%$ & 0.182 \\
\hline Relevant side branch & (153) $25.7 \%$ & (53) $21.7 \%$ & (100) $28.6 \%$ & 0.061 \\
\hline Intra-lesion angulation: & & & & 0.049 \\
\hline None & (77) $12.9 \%$ & (41) $16.8 \%$ & (36) $10.3 \%$ & \\
\hline$<45 \%$ & (205) $34.5 \%$ & (72) $29.5 \%$ & (133) $38.0 \%$ & \\
\hline $45-90 \%$ & (264) $44.3 \%$ & (110) $45.1 \%$ & (154) $43.7 \%$ & \\
\hline$>90 \%$ & (49) $8.2 \%$ & (21) $8.6 \%$ & (28) $8.0 \%$ & \\
\hline
\end{tabular}

Values are given as percentages of patients and numbers. * Statistically significant with $p<0.05 ;$ AHA/ACC - American Heart Association/ /American College of Cardiology

and intra-lesion angulation were significantly more frequent in the Rotablator group than in the Rotapro group. Annual frequencies of RA increased yearly from 2015 to 2019 (1.6-6.9\%, Suppl. Table 1).

\section{Characteristics related to $\mathrm{PCI}$ and RAS}

As shown in Table 3, PCI was performed with at least $6 \mathrm{~F}$ guides and upgraded up to $8 \mathrm{~F}$, based on the burr size used $(1.25-2.0 \mathrm{~mm})$. In the Rotapro group, radial access ( $40.70 \%$ vs. $28.70 \%$ ), $7 \mathrm{Fr}$ guides $(65.50 \%$ vs. $52.90 \%)$, and greater balloon sizes $(3.1 \pm 0.5 \mathrm{~mm}$ vs. $2.8 \pm 0.6 \mathrm{~mm})$ were more common. Both, number and total implanted stent lengths were similar in both groups (1.9 vs. 1.8 stents; 50.5 vs. $54.2 \mathrm{~mm}$ lengths). Significantly greater burrs were used in the Rotapro group.

\section{Primary endpoint}

The primary endpoint, in-hospital MACCE was comparable between both groups (3.7\% vs. $5.7 \%$, Rotapro vs. Rotablator, $\mathrm{p}=0.254$ ). Accordingly, the components of MACCE, such as rates of in-hospital mortality ( $2.4 \%$ vs. $2.6 \%, \mathrm{p}=0.923)$, periprocedural myocardial infarction $(0.4 \%$ vs. $0.9 \%, \mathrm{p}=0.647)$, target vessel revascularization $(2.9 \%$ vs. $3.7 \%, \mathrm{p}=0.566)$ and stroke $(0.0 \%$ vs. $0.3 \%, \mathrm{p}=1.0$ ) were comparable in both groups (Fig. 1). Within univariable analysis patients with acute coronary syndrome on admission had significantly higher in-hospital MACCE (odds ratio [OR] $3.29,95 \%$ CI 1.46-7.11, $\mathrm{p}=0.0005)$, nevertheless acute coronary syndrome was not an independent predictor for in-hospital MACCE after multivari- 
Table 3. Characteristics related to percutaneous coronary intervention (PCI) and rotational atherectomy system.

\begin{tabular}{lcccc}
\hline Overall procedural results & $\begin{array}{c}\text { Overall } \\
(\mathbf{n}=597)\end{array}$ & $\begin{array}{c}\text { Rotapro } \\
(\mathbf{n}=\mathbf{2 4 6})\end{array}$ & $\begin{array}{c}\text { Rotablator } \\
(\mathbf{n}=351)\end{array}$ & $\mathbf{P}$ \\
\hline Balloon diameter predilatation [mm] & $2.9 \pm 0.6$ & $3.1 \pm 0.5$ & $2.8 \pm 0.6$ & $0.0001^{*}$ \\
Balloon diameter postdilatation [mm] & $3.8 \pm 0.7$ & $3.9 \pm 0.6$ & $3.8 \pm 0.7$ & 0.07 \\
Inflation pressure predilatation [atm] & $21.7 \pm 11.9$ & $21.6 \pm 16.3$ & $21.8 \pm 7.9$ & 0.88 \\
Inflation pressure postdilatation [atm] & $21.6 \pm 5.5$ & $21.2 \pm 5.1$ & $21.8 \pm 5.9$ & 0.17 \\
Diameter stenosis pre PCI [\%] & $88 \pm 14$ & $87 \pm 15$ & $88 \pm 14$ & 0.70 \\
Diameter stenosis post PCl [\%] & $2 \pm 13$ & $1 \pm 10$ & $3 \pm 14$ & 0.07 \\
Number of stents implanted & $1.9 \pm 1.1$ & $1.9 \pm 1.1$ & $1.8 \pm 1.1$ & 0.78 \\
Stent diameter [mm] & $3.4 \pm 0.6$ & $3.5 \pm 0.5$ & $3.5 \pm 0.6$ & 0.27 \\
Overall stent length [mm] & $52.7 \pm 31.6$ & $50.5 \pm 30.3$ & $54.2 \pm 32.5$ & 0.23 \\
Burr size: & & & & $0.0001^{*}$ \\
$1.25 \mathrm{~mm}$ & $(130) 21.8 \%$ & $(26) 10.5 \%$ & $(104) 30.1 \%$ & \\
$1.50 \mathrm{~mm}$ & $(262) 44.0 \%$ & $(117) 47.4 \%$ & $(145) 42.2 \%$ & \\
$1.75 \mathrm{~mm}$ & $(172) 28.9 \%$ & $(87) 35.4 \%$ & $(85) 24.7 \%$ & \\
$2.00 \mathrm{~mm}$ & $(27) 4.5 \%$ & $(16) 6.7 \%$ & $(17) 3.0 \%$ & \\
Access site: & & & & $0.0024^{*}$ \\
Single radial access & $(201) 33.7 \%$ & $(100) 40.7 \%$ & $28.7 \%(102)$ & \\
Any femoral access & $(396) 66.3 \%$ & $(146) 59.3 \%$ & $(249) 71.3 \%$ & \\
Guiding catheter size: & & & & $0.0007^{*}$ \\
$6 \mathrm{Fr}$ & $(194) 31.5 \%$ & $(58) 23.6 \%$ & $(136) 38.8 \%$ & \\
$7 \mathrm{Fr}$ & $(349) 58.5 \%$ & $(161) 65.5 \%$ & $(186) 52.9 \%$ & \\
$8 \mathrm{Fr}$ & $(56) 9.4 \%$ & $(27) 11.0 \%$ & $(29) 8.3 \%$ & \\
\hline
\end{tabular}

Values are given as percentages of patients and numbers or as median and interquartile range. *Statistically significant with $p<0.05$

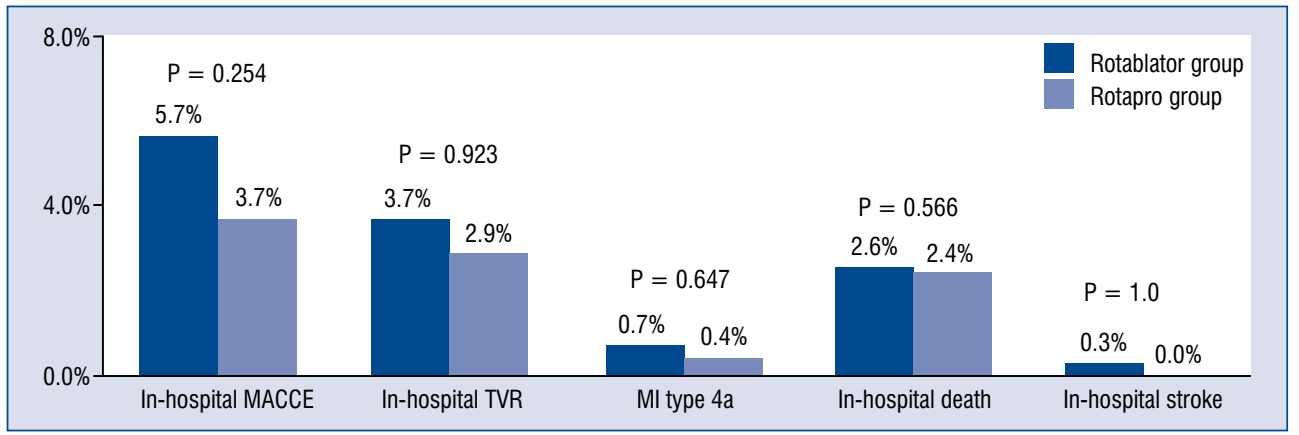

Figure 1. Components of the primary endpoint of in-hospital major adverse cardiovascular and cerebral events (MACCE) including pericardiocentesis during in the conventional Rotablator and Rotapro groups; $\mathrm{Ml}$ - myocardial infarction; TVR - target vessel revascularization.

able adjustment (OR 1.86, 95\% CI $0.65-4.65$, $\mathrm{p}=0.23)($ Table 4$)$.

\section{Secondary endpoints}

Technical success was comparable in both groups $(99.2 \%$ vs. $98.3 \%, \mathrm{p}=0.385)$. As shown in Table 5, procedural time (82.5 vs. $96 \mathrm{~min}$, $\mathrm{p}=0.0003)$, fluoroscopy time (30 vs. $38 \mathrm{~min}$, $\mathrm{p}=0.0001)$, contrast volume (210 vs. $290 \mathrm{~mL}$, $\mathrm{p}=0.0001)$ and radiation dosage (6129.5 vs. 9827 $\mathrm{cGy}^{*} \mathrm{~cm}^{2}, \mathrm{p}=0.0001$ ) were significantly lower in the Rotapro group. Clinically relevant perforation 
Table 4. Multivariable logistic regression analysis to predict the primary endpoint of in-hospital major adverse cardiac and cerebrovascular events.

\begin{tabular}{|c|c|c|c|c|c|c|}
\hline \multirow[t]{2}{*}{ Variable } & \multicolumn{3}{|c|}{ Univariable } & \multicolumn{3}{|c|}{ Multivariable } \\
\hline & OR & $95 \% \mathrm{Cl}$ & $\mathbf{P}$ & OR & $95 \% \mathrm{Cl}$ & $\mathbf{P}$ \\
\hline Acute coronary syndrome & 3.29 & $1.46-7.11$ & $0.005^{*}$ & 1.86 & $0.65-4.65$ & 0.23 \\
\hline History of CABG & 0.47 & $0.14-1.29$ & 0.15 & 0.48 & $0.14-1.31$ & 0.16 \\
\hline Positive stress test & 2.34 & $0.42-44.0$ & 0.38 & & - & - \\
\hline Excentric calcification & 0.89 & $0.42-1.97$ & 0.42 & & & - \\
\hline Intra-lesion angulation $>45 \%$ & 1.18 & $0.54-2.77$ & 0.68 & 1.17 & $0.49-3.11$ & 0.73 \\
\hline
\end{tabular}

*Statistically significant with $\mathrm{p}<0.05 ; \mathrm{CABG}$ — coronary artery bypass grafting; $\mathrm{Cl}$ — confidence interval; OR — odds ratio

Table 5. Study endpoints and major complications.

\begin{tabular}{|c|c|c|c|c|}
\hline & $\begin{array}{l}\text { Total number } \\
\qquad(\mathrm{n}=597)\end{array}$ & $\begin{array}{l}\text { Rotapro } \\
(n=246)\end{array}$ & $\begin{array}{l}\text { Rotablator } \\
(n=351)\end{array}$ & $\mathbf{P}$ \\
\hline \multicolumn{5}{|l|}{ Primary endpoint, (n) \% } \\
\hline In-hospital MACCE: & (29) $4.9 \%$ & (9) $3.7 \%$ & (20) $5.7 \%$ & 0.254 \\
\hline Mortality & (15) $2.5 \%$ & (6) $2.4 \%$ & (9) $2.6 \%$ & 0.923 \\
\hline MI type 4a & (4) $0.7 \%$ & (17) $0.4 \%$ & (3) $0.9 \%$ & 0.647 \\
\hline TVR & (20) $3.4 \%$ & (7) $2.9 \%$ & (13) $3.7 \%$ & 0.566 \\
\hline Stroke & (17) $0.2 \%$ & (0) $0.0 \%$ & (17) $0.3 \%$ & 1.000 \\
\hline \multicolumn{5}{|c|}{ Secondary procedural endpoints, (n) \% } \\
\hline Technical success & (589) $98.7 \%$ & (244) $99.2 \%$ & (345) $98.3 \%$ & 0.385 \\
\hline Procedural success & (568) $93.8 \%$ & (237) $95.5 \%$ & (331) $92.6 \%$ & 0.318 \\
\hline Procedural time [min] & $88[62-132]$ & $82.5[57-119]$ & $96[67-146.5]$ & $0.0003^{*}$ \\
\hline Fluoroscopy time [min] & $34[23-56]$ & $30[21-50]$ & 38 [25-63.5] & $0.0001 *$ \\
\hline Contrast volume used [mL] & $250[180-350]$ & $210[160-300]$ & $290[150-380]$ & $0.0001 *$ \\
\hline Dose area product $\left[\mathrm{cGy}^{*} \mathrm{~cm}^{2}\right]$ & 8011 [4758-14062] & 6129.5 [3563-9939] & 9827 [6098-16402] & $0.0001 *$ \\
\hline \multicolumn{5}{|l|}{ Major complications, (n) \% } \\
\hline Pericadiocentesis & (8) $1.3 \%$ & (2) $0.8 \%$ & (6) $1.7 \%$ & 0.348 \\
\hline Vascular access complication & (13) $2.1 \%$ & (8) $3.45 \%$ & (5) $1.46 \%$ & 0.206 \\
\hline
\end{tabular}

Values are given as percentages of patients and numbers or as median and interquartile range; *statistically significant with $p<0.05$; MACCE - major adverse cardiac and cerebrovascular events; MI - myocardial infarction; TVR - target vessel revascularization

with subsequent cardiac tamponade and pericardiocentesis occurred in $8(1.3 \%)$ patients. Coronary perforation requiring pericardiocentesis was numerically lower in the Rotapro group $(0.8 \%$ vs. $1.7 \%, \mathrm{p}=0.348$ ) (Table 5). Notably, parameters associated univariably with increased fluoroscopy time in each group are presented in Supplemental Tables 2 and 3. Within multivariable adjusted logistic regression models (Suppl. Table 4A, B). CTO-PCI (Rotapro: OR 10.5, 95\% CI 4.88-23.9, $\mathrm{p}=0.0001$, Rotablator: OR 5.22, 95\% CI 95\% 2.52$-11.11, \mathrm{p}=0.0001)$ and the use of any femoral or dual access (Rotapro: OR 2.73, 95\% CI 1.24-6.14, $\mathrm{p}=0.0118$, Rotablator: OR 2.68, 95\% CI 1.21-6.22, $\mathrm{p}=0.0151$ ) remained significantly associated with prolonged fluoroscopy time in both RAS groups.

\section{Discussion}

The present study was based on a large, consecutive cohort of patients undergoing RA comparing the feasibility, safety and in-hospital outcome of the new Rotapro and the former Rotablator system. The major findings of this study are: (a) The use of the new Rotapro RAS is safe and comparable with regard to in-hospital MACCE and procedural suc- 
cess to the former Rotablator RAS; (b) The new Rotapro RAS was associated with lower procedural and fluoroscopy time.

Increasing amounts of coronary calcification is a relevant pathology during cardiac catherization worldwide. Aging of coronary artery disease patients and rapidly developing techniques for the treatment of complex coronary lesions by PCI have increased the proportion of applied RA PCI to overcome severely calcified coronary lesions over the last decade. The incidence of PCI performed in moderate to severe calcified coronary lesions was recently estimated at $19.6 \%$ [11]. This incidence was estimated even higher in patients with coronary three vessel disease. Within the SYNTAX (Synergy Between Percutaneous Coronary Intervention with Taxus and Cardiac Surgery) trial, severely calcified coronary lesions were reported in $32.7 \%$ of patients with coronary artery bypass grafting and $24.9 \%$ of patients treated with PCI [12]. Furthermore, patients with calcified lesions are accompanied with relevant comorbidities including diabetes mellitus, dyslipidemia, arterial hypertension and chronic kidney disease [13].

The interventional treatment of severely calcified CAD is challenging and associated with higher rates of peri-procedural failures and complications compared to PCI of non- or less calcified lesions [5]. Increased operators' expertise, even in the application of devices to increase gear-related backup support (e.g. by extra support wires, guiding extension, high-pressure or modified balloons) are required to achieve optimal stent expansion. The technical principle of the RA device is to ablate the calcified atherosclerotic coronary plaque by advancing a high-speed diamond-incrusted elliptical burr in the coronary artery. RA has developed to the method of choice for lesion preparation to overcome severely calcified coronary artery disease within the past 30 years.

The new Rotapro RAS represents a more user-friendly handling for the operator due to an improved digital display, enhanced feedback, deceleration indicator, and on-side controller replacing the former foot pedal. Khalid et al. [14] recently reported data from the Food and Drug Administration Manufacturer and User Facility Device Experience (MAUDE) database during a period of more than 3 years. Adverse events and device-related issues were documented both for the Rotapro $(n=63)$ and Rotablator $(\mathrm{n}=363)$ RAS. It was demonstrated that RA devices are associated with higher incidences of coronary dissections, perforation and burr entrapment. Device-related issues including detachment and structural damages were reported in $39 \%$ in the Rotablator group, whereas device entrapment occurred in $47 \%$ in the Rotapro group. However, data on the procedural and clinical outcomes of patients treated with the new Rotapro RAS is lacking.

According to available research, the present study is the first dedicated analysis of RA using Rotapro. In the present trial, the in-hospital MACCE were comparable between both RAS. Technical and procedural success rates using RA were very high (98.7\% and $93.8 \%$, respectively) and did not show any meaningful trend. Notably, the new Rotapro system was associated with lower procedural time and less radiation exposure. Therefore, the present study demonstrated the safety and feasibility of the new Rotapro RAS.

\section{Limitations of the study}

This study was based on a retrospective non-randomized single-center registry. Furthermore, the indication for RA-PCI and the selected device was left to the operators' discretion and their technical expertise and selection bias may therefore not be excluded. Use of the former Rotablator RAS was associated with smaller $1.25 \mathrm{~mm}$ burrs, whereas severe complications were still comparable in RAS groups. A large prospective randomized controlled multi-center study is needed to investigate the optimal treatment strategy for plaque modification of uncrossable severely calcified lesions including the new Rotapro RAS.

\section{Impact on daily practice}

The new Rotapro RAS is user-friendly and was associated with lower procedural time, despite comparable in-hospital MACCE and procedural success rates.

\section{Conclusions}

The present study demonstrates the safety and efficacy of using the new Rotapro RAS, which was associated with comparable in-hospital MACCE, lower procedural time, radiation exposure and contrast use compared to the former generation of RAS.

Conflict of interest: Mohamed Ayoub, MD: reports consulting/speaker/proctoring honoraria honoraria from Boston Scientific, Ashai Intecc, Medtronic, Terumo; Miroslaw Ferenc, MD: reports consulting honoraria from Boston Scientific; Franz-Josef Neumann reports lectures fees paid to his institution from Amgen, Bayer Healthcare, Biotronic, 
Boehringer Ingelheim, Boston Scientific, Daiichi Sankyo, Edwards Lifesciences, Ferrer, Pfizer, Novartis, consultancy fees paid to his institution from Boehringer Ingelheim and grant support from Bayer Healthcare, Boston Scientific, Biotronic, Edwars Lifesciences, GlaxoSmithKline, Medtronic, Pfizer, Abbot Vascular; Kambis Mashayekhi reports consulting/speaker/proctoring honoraria from $\mathrm{Ab}$ bott Vascular, Ashai Intecc, AstraZeneca, Biotronik, Boston Scientific, Cardinal Health, Daiichi Sankyo, Medtronic, Teleflex, Terumo.

\section{References}

1. Li Q, He Y, Chen $\mathrm{Li}$, et al. Intensive plaque modification with rotational atherectomy and cutting balloon before drug-eluting stent implantation for patients with severely calcified coronary lesions: a pilot clinical study. BMC Cardiovasc Disord. 2016; 16: 112, doi: 10.1186/s12872-016-0273-8, indexed in Pubmed: 27230875.

2. Reifart N, Vandormael M, Krajcar M, et al. Randomized comparison of angioplasty of complex coronary lesions at a single center. Excimer Laser, Rotational Atherectomy, and Balloon Angioplasty Comparison (ERBAC) Study. Circulation. 1997; 96(1): 91-98, doi: 10.1161/01.cir.96.1.91, indexed in Pubmed: 9236422.

3. Onuma Y, Tanimoto S, Ruygrok P, et al. Efficacy of everolimus eluting stent implantation in patients with calcified coronary culprit lesions: two-year angiographic and three-year clinical results from the SPIRIT II study. Catheter Cardiovasc Interv. 2010; 76(5): 634-642, doi: 10.1002/ccd.22541, indexed in Pubmed: 20690152.

4. Rathore S, Matsuo H, Terashima M, et al. Rotational atherectomy for fibro-calcific coronary artery disease in drug eluting stent era: procedural outcomes and angiographic follow-up results. Catheter Cardiovasc Interv. 2010; 75(6): 919-927, doi: 10.1002/ ccd.22437, indexed in Pubmed: 20432398.

5. Abdel-Wahab M, Richardt G, Joachim Büttner H, et al. High-speed rotational atherectomy before paclitaxel-eluting stent implantation in complex calcified coronary lesions: the randomized ROTAXUS (Rotational Atherectomy Prior to Taxus Stent Treatment for Complex Native Coronary Artery Disease) trial. JACC Cardiovasc Interv. 2013; 6(1): 10-19, doi: 10.1016/j. jcin.2012.07.017, indexed in Pubmed: 23266232.

6. Abdel-Wahab M, Toelg R, Byrne RA, et al. High-speed rotational atherectomy versus modified balloons prior to drug-eluting stent implantation in severely calcified coronary lesions. Circ Cardiovasc Interv. 2018; 11(10): e007415, doi: 10.1161/CIRCINTERVENTIONS.118.007415, indexed in Pubmed: 30354632.

7. Mintz GS, Popma JJ, Pichard AD, et al. Patterns of calcification in coronary artery disease. A statistical analysis of intravascular ultrasound and coronary angiography in 1155 lesions. Circulation. 1995; 91(7): 1959-1965, doi: 10.1161/01.cir.91.7.1959, indexed in Pubmed: 7895353.

8. Barbato E, Carrié D, Dardas P, et al. European Association of Percutaneous Cardiovascular Interventions. European expert consensus on rotational atherectomy. EuroIntervention. 2015; 11(1): 30-36, doi: 10.4244/EIJV11I1A6, indexed in Pubmed: 25982648.

9. Safian RD, Feldman T, Muller DW, et al. Coronary angioplasty and Rotablator atherectomy trial (CARAT): immediate and late results of a prospective multicenter randomized trial. Catheter Cardiovasc Interv. 2001; 53(2): 213-220, doi: 10.1002/ccd.1151, indexed in Pubmed: 11387607.

10. Thygesen K, Alpert JS, Jaffe AS, et al. Third universal definition of myocardial infarction. J Am Coll Cardiol. 2012; 60: 1581-98, doi: 10.1016/j.jacc.2012.08.001.

11. Lee MS, Yang T, Lasala J, et al. Impact of coronary artery calcification in percutaneous coronary intervention with paclitaxeleluting stents: Two-year clinical outcomes of paclitaxel-eluting stents in patients from the ARRIVE program. Catheter Cardiovasc Interv. 2016; 88(6): 891-897, doi: 10.1002/ccd.26395, indexed in Pubmed: 26756859.

12. Serruys PW, Morice MC, Kappetein AP, et al. Percutaneous coronary intervention versus coronary-artery bypass grafting for severe coronary artery disease. N Engl J Med. 2009; 360(10): 961-972, doi: 10.1056/NEJMoa0804626, indexed in Pubmed: 19228612.

13. Oei HHS, Vliegenthart R, Hofman A, et al. Risk factors for coronary calcification in older subjects. The Rotterdam Coronary Calcification Study. Eur Heart J. 2004; 25(1): 48-55, doi: 10.1016/j. ehj.2003.10.008, indexed in Pubmed: 14683742.

14. Khalid N, Javed H, Shlofmitz E, et al. Adverse events and modes of failure related to rotational atherectomy system: the utility of the MAUDE database. Cardiovasc Revasc Med. 2021; 27: 57-62, doi: 10.1016/j.carrev.2020.08.038, indexed in Pubmed: 33071196. 